Patient Education and Counseling, 7 (1985) 395-407

Elsevier Scientific Publishers Ireland Ltd.

\title{
EVALUATION OF A MINIMAL-CONTACT SMOKING CESSATION PROGRAM IN A HEALTH CARE SETTING
}

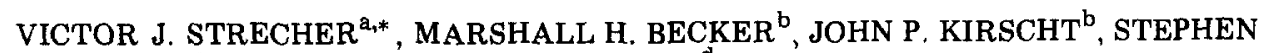
A. ERAKER ${ }^{\text {C }}$ and ROBIN P. GRAHAM-TOMASI ${ }^{\mathrm{d}}$

${ }^{\mathrm{a}}$ Department of Health Education, University of North Carolina, Chapel Hill, $N C,{ }^{\mathrm{b}}$ Department of Health Behavior and Health Education, University of Michigan, Ann Arbor, MI ${ }^{\mathrm{c}}$ Department of Medicine, Veterans Administration Medical Center, Salt Lake City, UT and ${ }^{\mathrm{d} D i v i s i o n}$ of Disease Prevention and Control, Minnesota Department of Health, Minneapolis, $M N$ (U.S.A.)

(Received April 19th, 1985)

(Accepted June 26th, 1985)

ABSTRACT

A controlled evaluation of a minimal-contact smoking cessation intervention was conducted with 213 inpatients and outpatients at a Veterans Administration Medical Center (VAMC). The intervention had three components: Brief consultation from a health practitioner; administration of a selfhelp smoking cessation manual; and provision of an incentive to adhere to recommendations in the manual. Enrollment procedures differed from those of many other smoking-intervention trials in that, instead of enrolling only smokers who were motivated to quit, all patients who smoked and who would normally be considered eligible for a smoking-cessation intervention were included. The evaluation examined acceptability of the program to patients who smoked, overall effectiveness of the intervention, and efficacy of the intervention for specific patient demographic, social status, and health status groups.

The program had a high degree of acceptance by patients who smoked, with over $60 \%$ agreeing to participate and take home the self-help smokingcessation manual. The program was effective in getting patients to reduce their daily smoking, and marginally effective in influencing smoking cessation, with some patient groups exhibiting higher cessation rates than others. Special problems to be considered when attempting to influence groups of smokers at high levels of psychological stress and with low levels of education and income - factors normally associated with high rates of smoking and failure in traditional smoking-cessation programs - are discussed in light of the results obtained.

*To whom reprint requests should be sent. 
Key words: Smoking cessation - Self-help

\section{INTRODUCTION}

Health care settings, such as hospitals and medical centers, have frequently , been the loci of smoking-cessation programs for patients and for the general public. Many hospitals conduct their own smoking cessation clinics; others offer programs to which health care providers may refer their patients who smoke. Most programs are designed to serve smokers already motivated to quit; responding to a newspaper/flyer/poster advertising of a smokingcessation program, these smokers choose to invest what is often a substantial amount of time and money in order to participate. Such a procedure for quitting is not appropriate for the large majority of smokers. Surveys assessing the willingness of smokers to try various cessation strategies have found relatively-intensive methods (e.g. counseling, group discussion, and clinic approaches) to be the least-acceptable modes of quitting [1-3]. Of those reportedly willing to enter such programs, few actually go beyond behavioral intention [4]. Clearly, if smoking-cessation programs are to have an impact on the health of the public, efforts must be directed at reaching greater numbers of smokers with more acceptable programs.

Hospital-based smoking cessation programs for patients who smoke might gain wider acceptance if health care providers initiated the anti-smoking effort on a one-to-one basis. The potential strength of these practitioners' interventions lies both in the large number of smokers they see and in their credibility as a source of health information. [5-7]. The effectiveness of practitioners' efforts may be enhanced if accompanied by cognitive and behavioral techniques [8], which are most acceptable when presented in a self-help mode. True self-help programs do not involve contact with a therapist or practitioner; the participant relies exclusively on written or taped materials. 'Minimal-contact' programs require some professional contact, but primary reliance is still placed upon self-help materials [8]; these interventions may utilize a combination of brief practitioner consultation with comprehensive self-help booklets or manuals, or with less comprehensive written information such as pamphlets or brochures. When conducted in health care settings, minimal-contact programs have the potential to reach large numbers of smokers at relatively low cost; in contrast to high-contact interventions, they require less time and expense from the smoker, can be used beyond the clinical setting, and can be initiated with every patient who smokes cigarettes not just those who are motivated to quit.

This paper presents findings from an evaluation of a minimal-contact smoking-cessation intervention administered to patients at a Veterans Administration Hospital. Issues addressed in the paper include: (1) Degree of program acceptance; (2) rates of smoking reduction and cessation as a result 
of the program; (3) influences of patients' demographic characteristics, social status, and health status on rates of smoking reduction or cessation.

\section{METHODS}

\section{Sample and design}

Subjects were male inpatients $(n=125)$ and outpatients $(n=88)$ at a VAMC. Enrollment procedures differed from those of many other smokingintervention trials in that, rather than recruiting only those who were motivated to respond to an announcement of program availability, all patients who smoked and who would normally be considered eligible for a smokingcessation project were actively sought. Excluded were patients who were: Terminally ill; unable to read or to understand educational materials; in the psychiatric ward or clinic; undergoing treatment for alcohol or drug addiction. Since follow-up interviews were to be conducted by telephone, patients not possessing telephones were also excluded. Based on the number of patients initially approached and on admission records, those ultimately included represented about $80-85 \%$ of all potential subjects. It was impossible to determine the exact number of potential subjects, since no acceptable mechanism existed for identifying all incoming patients who smoked.

Patients were assigned (by 3-month time-intervals) to either an intervention group ( $n=119$ ) or a 'usual care' control group $(n=94)$. Purely random allocation to intervention or control group would have created a high likelihood of between-group contamination, since most patients were readily able to talk with one another about their various treatments. All groups were initially administered a questionnaire (by an interviewer) which assessed number of cigarettes smoked daily as well as characteristics thought to be associated with smoking and with smoking-cessation behavior. Patients were also asked whether they wished to quit smoking within the calendar year. Those in the intervention group who answered 'yes' or 'don't know' were administered the smoking intervention. Patients assigned to the control group who also responded 'yes' or 'don't know' were used as a comparison to the intervention group; these patients received the care usually given to smokers at the VAMC. Usual care, while not explicitly examined, appeared to vary greatly by the health practitioners seen and the health status of the patient. At the time of the initial interview, subjects were not aware of the intervention or of whether they were in an intervention or control group. The number of cigarettes smoked daily was assessed again for both experimental and control groups approximately 3 months following discharge from the VAMC.

\section{The study intervention}

The intervention consisted of a minimal-contact smoking-cessation program designed for use in a health care setting. The program's three basic components involved provision of: Consultation from a health-care practitioner (regular or student); a self-help smoking-cessation manual; and an incentive to comply with the manual. 
Practitioner consultation. A consultation procedure was developed specifically for this smoking-cessation program and used to instill commitment to quit smoking. The consultation was scheduled as close as possible to the patient's discharge from the VAMC because of the emphasis that the selfhelp kit places on awareness of environmental cues which trigger the smoking habit (cues in the hospital are often not the same as those which present themselves in the environment of the subject's home). In most cases, only the first day or two of the self-help diary were completed by the patient while in the hospital.

Five women served as counselors: A full-time nurse at the VAMC; a fulltime health educator with an M.P.H. degree; two M.P.H. students majoring in health education; and a senior premedical student. No significant differences in smoking cessation rates were found among patients seen by the different counselors. Consultation procedures and skills were taught to these women via a training manual and tutorial. The scheme developed for this program reflects a synthesis of theoretical models of decision-making $[12,13]$ as well as practical consultation techniques and strategies from the behavioral counseling literature [14]; it was designed to facilitate patient decisionmaking, selectively reinforced for self-arrived-at decisions. The counselor also served to clarify the complex network of opposing forces governing the smoking decision.

The consultation process employed four basic steps to motivate the patient. The first step examined the patient's rationales for his smoking behavior (i.e. reasons for his decision to take up smoking and reasons governing his present smoking). The purpose of this exercise was to make the patient sensitive to the decision-making process, as well as to begin developing a greater awareness of the smoking habit. The second step explored, from the patient's perspective, consequences of various smoking decisions. What events might occur if the patient chose a particular alternative? If the event occurred, how would it affect the patient's lifestyle? In most cases, the counselor emphasized functional rather than disease consequences of smoking; faulty or unrealistic outcome expectations were managed correctively. The third step introduced the self-help smoking-cessation kit. The initial series of activities described in the self-help kit (a relaxation exercise, a stop-smoking contract, and the first day of a 3-week diary) was completed with the patient. The final step reviewed the consultation process: the alternative decisions discussed; the advantages and disadvantages of those alternatives; the new decision made; and the probable immediate and long-term consequences of that decision. The patient was then assured by the counselor of future support through weekly phone calls to the patient's home.

Diary self-help kit. The self-help kit developed for this population presented simple daily activities aimed at quitting smoking, contained words most veterans could understand, and was printed in type sufficiently large to enable the patients with eyesight problems to read the manual. The kit employed a consistent format for each day of the diary in the expectation that such repetition would be more readily accepted into the normal routine of the 
patient. Reading level was set at roughly fourth-to-sixth grade, depending on the readability test used [15]. Also, pictures used in the self-help kit depicted people with whom veterans would be likely to identify.

The kit contained four parts, to be completed during the consultation. The first exercise was a smoking-awareness test [16] which measured the level of cigarette craving a smoker experienced during specific environmental or psychological states; its purpose was to give the smoker greater awareness of his habit. Next, the first day of the diary portion was filled out. Each day of the diary contained both a section in which to monitor daily cigarette smoking and a set of sample instructions for the day. Once the first day's entries were made and the remaining pages presented and described, the counselor had the patient complete a simple contract to quit smoking (cosigned by the counselor). Finally, a deep-breathing exercise was explained and performed. This exercise was to be done every morning during the intervention period, and was also to be used as a substitute for smoking anytime the patient felt tense or anxious; it was practiced with the patient as a closing to the consultation.

The self-help kit employed a hierarchy of skills development over the 3week period of the diary. Skills related to quitting smoking were presented in a stepwise format, with each new task progressively more difficult than the previous one. Initial confidence was gained through completion of relatively simple activities; thus, the first task involved the development of greater awareness of the smoking habit, allowing smokers to become more conscious of environmental cues influencing the pattern of their smoking habit. The second major task was developing alternative activities for coping with specific environmental cues, while the third task involved applying these skills to cease smoking completely (timed to occur between days 8 and 10 of the 3-week diary kit). The final task required the subject to reorganize his responses to cues which influenced cravings to smoke. Following completion of each major performance task, self-rewards were promoted within the diary kit.

Diary compliance. Adherence to the self-help kit's daily instructions was crucial for long-term program success; so, in order to improve upon traditionally low self-help participation rates, a reward system was built into the program. At the end of each week of the 3-week diary, a page was included instructing the participant to tear out the preceding completed page-days and mail them in stamped, VAMC-addressed envelope stapled to the back of the kit. In exchange for returning each week of diary pages, the participant received a free State lottery ticket worth $\$ 1$. Lottery tickets had considerable appeal to this group of patients, apparently because they were free and created the possibility of high reward.

In addition to offering lottery tickets, the counselor telephoned each subject at the end of each week of the self-help kit diary. Participants were asked about their progress in the program (and were given encouragement), and about whether the previous week's diary pages had been sent back to the hospital. If the patient had not returned the appropriate diary pages, reasons 
for not doing so were elicited, and encouragement to continue with the program was provided. Finally, a phone call was made at the end of the intervention phase to assure patients of continued support.

\section{Measures}

Smoking status. Number of cigarettes smoked per day was initially obtained by questionnaire response (on average, subjects reported smoking 24 cigarettes per day and had been smoking for 34 years). Smoking status after 3 months was assessed using a variation of the 'Bogus Pipeline' method [17]. Subjects were first asked when their next VAMC appointment was scheduled. The interviewer then stated that a simple chemical test might be administered during the subject's next visit (future follow-ups using chemical assessment of smoking status are planned for this group of patients). Following this statement, subjects were asked how many cigarettes, on average, they smoked per day (interviewers were not told whether the subject was in the intervention or control group). The 3-month follow-up smoking measure was then divided by the initial questionnaire smoking measure to determine percent change in number of cigarettes smoked. Throughout these assessments, all interviewers had the strong impression that the subjects were nearly always being honest about their cigarette consumption. Special effort was made to avoid projecting preferences for any particular answer; e.g. subjects were not asked whether they had cut back or quit smoking - only for the number of cigarettes per day that they smoked. It was also felt that: (1) The validity of self-reported smoking behavior would be greater if the subject was asked only about present behavior as opposed to a change in behavior over time; and (2) since patients had received only a minimal-contact intervention by a health care practitioner, they would feel little pressure to misrepresent their smoking status.

Health status and demographic characteristics. Information on these variables was acquired by the questionnaire administered prior to the intervention. A measure of functional impairment was constructed based on reports of existence and duration of impairment of normal physical activities. Four activities were reviewed: traveling around the community; engaging in vigorous activities (e.g. lifting heavy objects); walking around the block; and working around the house. Duration of impairment was assessed as: less than 1 month; 1-3 months; and greater than 3 months (the questions were derived from measures employed in the Rand Health Insurance Study [18]). These items were combined to form an overall index of functional impairment status by multiplying individual activity scores by duration scores and then dichotomizing the measure to form a low-high contrast. Sixty-six percent of subjects were characterized as having low functional impairment while $34 \%$ had high functional impairment. Demographic characteristics assessed included age (23\% were less than 39 years old, $49 \%$ were between 40 and 59 years old, and $28 \%$ were at least 60 years old); education ( $37 \%$ had less than a high school education, $31 \%$ had a high school education, and $32 \%$ had greater than a high school education); income (42\% earned less than $\$ 6,000$ 
per year, $33 \%$ earned between $\$ 6,000$ and $\$ 12,000$ per year, and $25 \%$ earned more than $\$ 12,000$ per year); and race ( $88 \%$ were white, $11 \%$ were black, and $1 \%$ were other races).

\section{RESULTS}

Study findings are presented in the following order: acceptability of the intervention, overall effects of the intervention, and effects of the intervention for specific health status and demographic subgroups.

\section{Program acceptibility}

The program was evaluated for acceptability by determining the number of patients expressing a desire to quit, and, of those patients, the number accepting the intervention when offered. Results are diagrammed in Fig. 1. Of the 119 patients in the intervention group, 24 (20\%) indicated that they did not wish to quit smoking within the calendar year (these patients were not offered the intervention). Of the 95 patients remaining, 23 patients (19\% of the total) refused the intervention, leaving 72 patients who accepted the proffered smoking-cessation intervention. Thus, in terms of the procedures for initiating the program described earlier, $61 \%$ of patients who smoked and would normally be considered for smoking-cessation programs accepted this particular program.

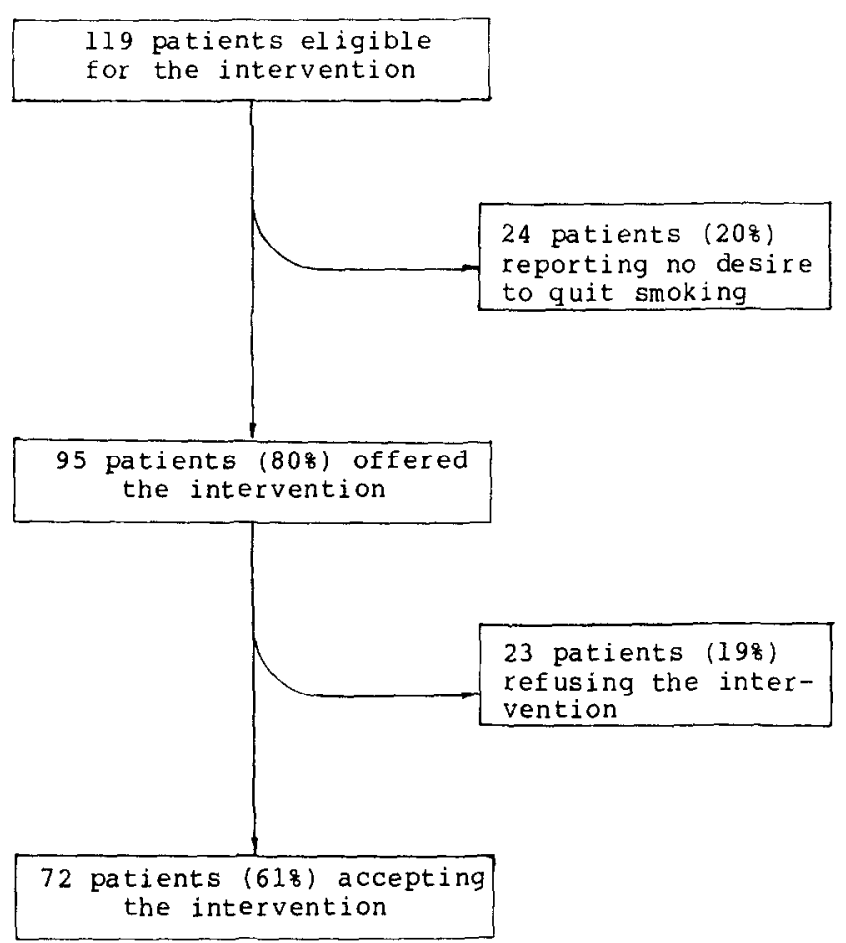

Fig. 1. Diagram of patient acceptance of the smoking cessation intervention. 


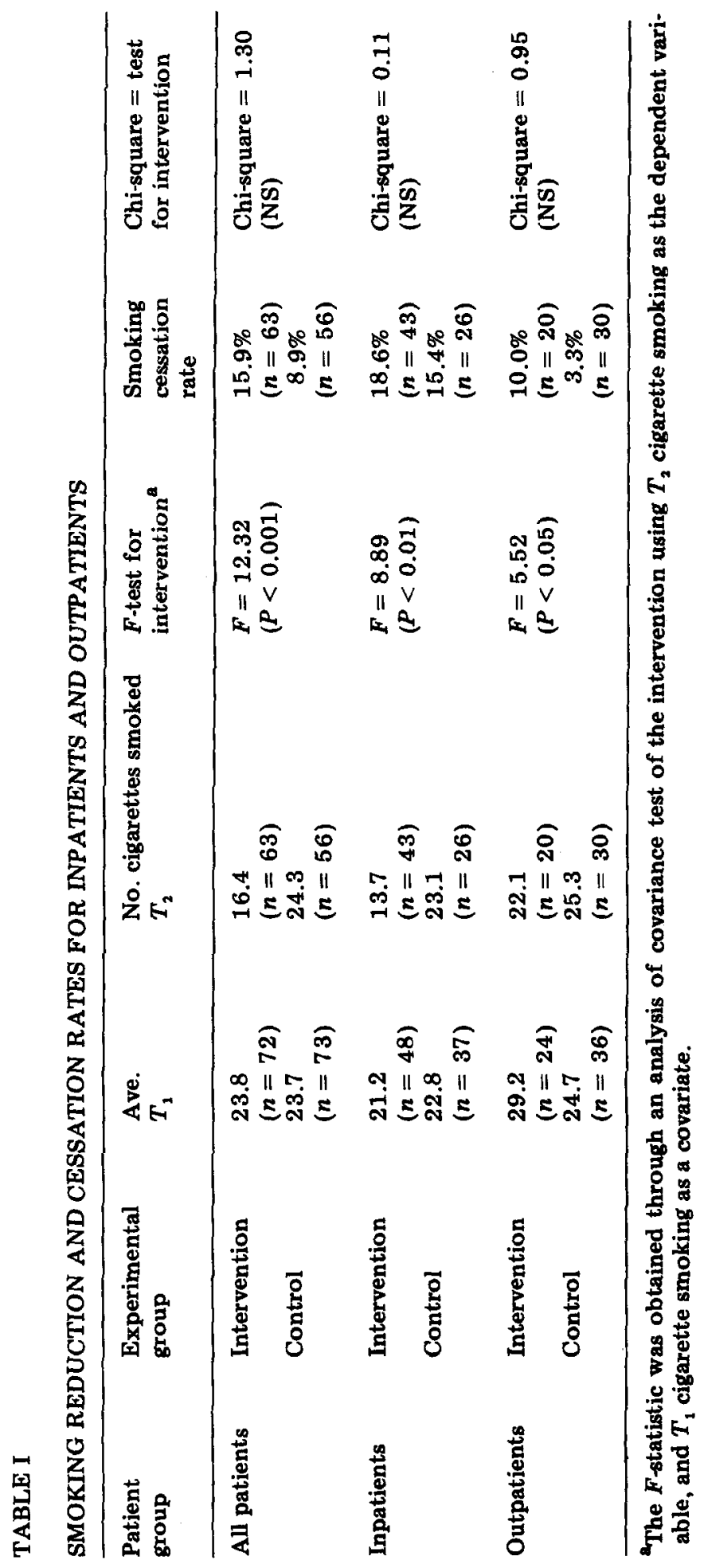




\section{Overall intervention effects}

To examine the effects of the intervention, subjects who were offered and accepted the intervention were compared with control-group subjects who responded 'yes' or 'don't know' to the question of whether they wished to quit smoking within the calendar year (i.e. those subjects within the control group who, had they been in the intervention group, would have been offered the intervention). We do not know (and thus, cannot exclude) those control subjects who would have refused the offered intervention; this contrast is, therefore, a liberal evaluation of the smoking-cessation program, since the control group includes those who might have refused the intervention. Since the number of patients in the intervention group who refused the intervention after responding 'yes' or 'don't know' to whether they wished to quit smoking was relatively small (24\%), this bias is not likely to be a large one.

Of the 72 subjects who received the intervention, $63(88 \%)$ were recontacted 3 months later to determine follow-up smoking status. Of the 73 subjects in the control group, $56(77 \%)$ were recontacted 3 months later. Table I presents rates of smoking reduction and cessation for inpatients, outpatients and all patients combined.

Reported daily cigarette smoking was significantly reduced for inpatients $(F=8.89 ; P<0.01)$ and for outpatients $(F=5.52 ; P<0.05)$, as well as for both groups combined $(F=12.32 ; P<0.001)$. Smoking-cessation rates, however, were not significantly higher for the intervention group than for the control group in any of the patient groupings examined. Inpatients had

\section{TABLE II}

RATES OF SMOKING CESSATION AND REDUCTION BY LEVEL OF FUNCTIONAL IMPAIRMENT, STRATIFIED BY EXPERIMENTAL GROUP

The chi-square tests of the intervention for patients reporting low functional impairment were not significant for smoking cessation $\left(x^{2}=0.12\right)$ or reduction $\left(\chi^{2}=0.02\right)$. The chisquare tests of the intervention for patients reporting high functional impairment were significant for smoking cessation $\left(x^{2}=4.97 ; P<0.05\right)$ and reduction $\left(x^{2}=10.92 ; P<\right.$ 0.005 ).

\begin{tabular}{|c|c|c|c|}
\hline \multirow{2}{*}{$\begin{array}{l}\text { Experimental } \\
\text { group }\end{array}$} & \multirow{2}{*}{$\begin{array}{l}\text { Functional } \\
\text { impairment }\end{array}$} & \multicolumn{2}{|c|}{$\%$ smoking reduction } \\
\hline & & $\geq 50 \%$ & $100 \%$ \\
\hline Intervention & $\begin{array}{l}\text { Low } \\
\text { High }\end{array}$ & $\begin{array}{l}27.3 \% \\
(n=44) \\
52.6 \% \\
(n=19)\end{array}$ & $\begin{array}{l}9.1 \% \\
(n=44) \\
31.6 \% \\
(n=19)\end{array}$ \\
\hline Control & $\begin{array}{l}\text { Low } \\
\text { High }\end{array}$ & $\begin{array}{c}25.7 \% \\
(n=35) \\
5.0 \% \\
(n=20)\end{array}$ & $\begin{array}{c}11.4 \% \\
(n=35) \\
4.8 \% \\
(n=21)\end{array}$ \\
\hline
\end{tabular}


markedly higher overall rates of smoking cessation and reduction than did outpatients. This result was obtained regardless of whether or not the patient had received the intervention.

\section{Differences between questionnaire measures}

Relationships of the study's psychosocial measures to changes in number of cigarettes smoked are presented elsewhere [19]. It was noted earlier that the study questionnaire also assessed functional health status, perceived health status and demographic characteristics (age, education, income and race). Only functional status was found to be associated with success of the intervention. Table II presents rates of smoking cessation and reduction for high and low levels of functional impairment, stratified by experimental groups.

Subjects reporting a relatively low level of functional impairment had very similar rates of smoking reduction and cessation. However, among those with higher levels of functional impairment, participants who received the intervention reported far higher rates of smoking reduction and cessation than did those in the control group. (While a measure of perceived overall health status was found to be significantly associated with functional impairment, the former measure was not related to smoking outcomes.)

\section{DISCUSSION}

This paper presents results from a controlled trial of a smoking-cessation intervention administered to inpatients and outpatients using a VAMC. We were interested not only in whether the program was effective, but also in whether patients would accept it - the crucial first step in any public health education intervention. In this regard, we found most patients not only indicating a willingness to quit but also agreeing to participate in the program and to take home the self-help smoking-cessation materials.

Only $20 \%$ of all patients eligible for the intervention group reported not wishing to quit smoking within the calendar year. The minimal-contact aspect of the intervention seems to have kept most subjects in the program. Consultations were relatively brief and did not interfere with the normal activities of the patients or of the hospital employees. The self-help kit was also found to be a generally acceptable component of the program. Only $24 \%$ of subjects receiving the consultation subsequently refused the kit; and, of those who agreed to take the kit home, $46 \%$ of the inpatients and $54 \%$ of the outpatients completed and returned pages of the kit's diary to the hospital as instructed. Those sending back the pages, however, were not the only subjects who used the book to quit or to cut back on their smoking.

While the cessation rates obtained were, in many cases, similar to those found in other evaluations (evaluation of American Lung Association cessation and maintenance manuals [20] on a self-selected group of predominantly middle class subjects found a $12 \%$ self-reported cessation rate after 3 months), high rates of cessation among the usual care inpatients tended to wash out 
the effects of the intervention. Perhaps usual care inpatients received smoking cessation efforts from health providers extrinsic to the study. Also, a larger sample size (particularly among outpatients) would have improved the power of the statistical tests employed, which, in turn, might have resulted in more significant cessation effects. Given the final sample size of those followed-up, the statistical power of detecting a difference in smoking cessation rates at a alpha level of 0.05 if a $10 \%$ difference actually existed due to the program was less than $50 \%$.

Significant reductions in cigarette smoking were observed in both the inpatient and outpatient groups. Reduction in smoking can have a meaningful influence on the smoker's health as wcll as on his future ability to quit smoking altogether. Epidemiologic research $[21,22]$ suggests that a doseresponse relationship exists between smoking and health effects. Hughson and colleagues [23] found increased survival rates among patients who had quit or reduced their smoking. Clearly, while quit rates are highly desired outcomes in most smoking-intervention research, smoking reduction is also important, particularly for those subjects who have been heavy smokers for a long period of time. Research by Glasgow and colleagues [24] suggests that heavy smokers can, in fact, significantly cut back on their smoking for at least 6 months. Long-term reduction may allow the smoker to gradually reduce the need to maintain a high concentration of nicotine in the blood and, at the same time, to slowly acquire feelings of control and confidence relative to coping with situations which stimulate the urge to smoke.

The intervention was found to be effective among those reporting high levels of functional impairment. For these subjects (roughly $30 \%$ of the intervention group), both cessation and reduction rates were significantly higher than those found for their respective control groups. These findings, combined with the higher cessation rate among inpatients than outpatients, tend to support the conclusion (drawn from Pederson's review [6] of physician efforts to get patients to quit smoking) that success rates improve with increasing severity of patients' illnesses. However, this conclusion is not completely substantiated by this study for two reasons: (1) Those reporting high functional impairment who did not receive the intervention had the lowest cessation and reduction rates; and (2) while functional impairment was an important factor related to the effectiveness of the intervention, perceived health status was not (the two variables were associated with one another, but acted differently with respect to their influence on smoking cessation). It seems that the manifestation of poor health status presents more powerful motivation to change smoking behavior than does health status itself. As Dubos [25] states:

... the words health and disease are meaningful only when defined in terms of a given person functioning in a given physical and social environment. The nearest approach to health is a physical and mental state fairly free of discomfort and pain, which permits the person concerned to function as effectively and as long as possible in the envirunment where chance or choice has placed him.

(p.351) 
In summary, a minimal-contact smoking-cessation program developed for use in a health-care setting was evaluated and found to have a high degree of acceptance by patients who smoke. The program appears to be effective in getting patients to reduce their daily smoking, and is also marginally effective in influencing smoking cessation, with some patient groups achieving relatively high rates of smoking cessation and others not. Success with this particular group of smokers is especially noteworthy, since they are typified as having low levels of education and income, and as having high levels of psychosocial stress - all factors usually associated both with high rates of smoking and with high likelihood of failure in traditional smoking-cessation programs.

\section{ACKNOWLEDGMENTS}

This research was supported by a predoctoral fellowship from the Health Services Research and Development Service of the Veterans Administration to Dr. Strecher and by a grant from the Veterans Administration to Dr. Eraker.

\section{REFERENCES}

1 Gallup Opinion Index: Public puffs on after ten years of warnings. Report No. 108, Princeton, NJ, June 1974, pp 20-21.

2 Schwartz JE, Dubitzky M: Expressed willingness of smokers to try 10 smoking withdrawal methods. Public Health Rep 1967, 82: 855-861.

3 Pechacek TF, Danaher BG: How and why people quit smoking: A cognitive-behavioral analysis. In Kendall P, Hollow S (Ed.): Cognitive-Behavioral Interventions: Theory, Research, and Procedures. New York: Academic Press, 1979, pp 389-422.

4 Eiser JR, Sutton SR: Smoking as a subjectively rational choice. Addict Behav 1977; 2: 129-134.

5 Russell MAH, Wilson C, Taylor C, Baker CD: Effect of general practitioners' advice against smoking. Br Med J 1977; 2: 231-235.

6 Pederson LL: Compliance with physician advice to quit smoking: A review of the literature. Prev Med 11 1982; 11: 71-84.

7 Leventhal $\mathrm{H}$, Cleary P: The smoking problem: A review of the research and theory in behavioral risk modification. Psychol Bull 1981; 88: 370-405.

8 Strecher VJ: A minimal-contact smoking cessation program for a health care setting. Public Health Rep 1983; 5: 497-502.

9 Glasgow RE, Rosen GM: Behavioral bibliotherapy: A review of self-help behavioral therapy manuals. Psychol Bull 1978; 85: 1-23.

10 Glasgow RE, Schafer L, O'Neill HK: Self-help books and amount of therapist contact in smoking cessation programs. J Consult Clin Psychol 1981; 5: 659-667.

11 Pederson LL, Baldwin N, Lefcoe NM: Utility of behavioral self-help manuals in a minimal-contact smoking cessation program. Int J Addict 1981; 16: 1233.

12 Horan JJ: Counseling for Effective Decision-Making - A Cognitive-Behavioral Perspective. Massachusetts: Duxbury Press, 1979.

13 Janis IL, Hoffman D: Effective partnerships in a clinic for smokers. In Janis I (Ed.), Counseling on Personal Decisions. New Haven: Yale University Press, 1982.

14 Brammer LM: The Helping Relationship: Process and Skills. New Jersey: Prentice Hall, 1979. 
15 United States Department of Health, Education, and Welfare: Readability testing in cancer communications, DHEW Publication No. 79-1689, Washington, DC: U.S. Government Printing Office, 1979.

16 United States Department of Health, Education, and Welfare: Why do you smoke? DHEW Publication No. 80-1811-A. Washington, DC: U.S. Government Printing Office, 1980 .

17 Evans RI, Hansen WB, Mittlemark MB: Increasing the validity of self-reports of smoking behavior in children. J Appl Psychol 1977; 72: 521-523.

18 Brook RH, Ware JE: Overview of adult health status measures fielded in Rand's Health Insurance Study. Med Care 1979; (Suppl) 17.

19 Strecher VJ, Becker MH, Kirscht JP, Eraker SA, Graham-Tomasi RP: Psychosocial aspects of changes in cigarette smoking behavior. Pat Educ Couns 1985; 7: 249-262.

20 Davis AL, Faust $R$, Ordentlich $M$ : Self-help smoking cessation and maintenance programs: A comparative study with 12-month follow-up by the American Lung Association. Am J Public Health 1984; 74 : 1212-1217.

21 Kuller L, Meilahn E, Townsend M, Weinberg G: Control of smoking from a medical perspective. In Breslow L, Fielding J, Lave, L (Ed.): Annual Review of Public Health. Palo Alto: Annual Reviews, Inc., 1982, p 3.

22 Rogot E: Smoking and life expectance among U.S. veterans. Am J Public Health 1978; 68: $1023-1025$.

23 Hughson WG, Mann JI, Tibbs DJ, Woods HF, Walton I: Intermitten claudication: Factors determining outcome. Br Med J 1978; 1: 1377-1379.

24 Glasgow RE, Klesges RC, Godding PR, Gegelman R: Controlled smoking, with or without carbon monoxide feedback, as an alternative for chronic smokers. Behav Ther $1983 ; 14: 386-397$.

25 Dubos R: Man adapting. New Haven: Yale University Press, 1965. 